\title{
A Potential Use of Color Ultrasound as a Tool for Reproductive Management: New Observations Using Color Ultrasound Scanning that were not Possible with Imaging Only in Black and White
}

\author{
Akio MIYAMOTO' ${ }^{1)}$, Koumei SHIRASUNA ${ }^{1)}$, Ken-Go HAYASHI'), \\ Daichi KAMADA ${ }^{1)}$, Chiho KAWASHIMA ${ }^{1)}$, Etsushi KANEKO ${ }^{1)}$, \\ Tomas J. ACOSTA ${ }^{3)}$ and Motozumi MATSUI ${ }^{2)}$ \\ ${ }^{1)}$ Graduate School of Animal and Food Hygiene and ${ }^{2)}$ Department of Clinical Veterinary \\ Science, Obihiro University of Agriculture and Veterinary Medicine, Obihiro 080-8555 and \\ ${ }^{3)}$ Laboratory of Reproductive Endocrinology, Graduate School of Natural Science and \\ Technology, Okayama University, Okayama 700-8530, Japan
}

\begin{abstract}
Ultrasonography (US) has been applied to the ovary and the uterus of domestic animals from the late 1980s, and established in 1990s as a practical tool for animal production. US made it possible to detect pregnancy at a very early stage and, most importantly, to observe the real-time dynamics of follicular development and hence the discovery of follicular waves. This has greatly contributed to our understanding of ovarian physiology and helped us to develop several "pin-point" protocols for hormonal treatment. While US may not seem to fit preconceived ideas of a "green" technology, it does not contravene environmental priorities, and it is non-invasive ("ethical") and non-hormonal ("clean"). Using the US technology that is now commercially available at a reasonable price, we are able to estimate the best timing for AI and this allows us to plan either the use of precisely-timed nutritional supplements for fetal development or an immediate 2nd AI service to achieve a better economic efficiency. During the last few years, we have also begun to be able to observe in detail the local blood flow in individual ovarian follicles and CL using color Doppler ultrasonography in the cow. From the series of observations, we have found that: 1) the change of blood supply to an individual follicle closely relates to the dynamics of follicular growth and atresia; 2) the local blood flow detected in the theca externa of mature follicles rapidly increases around the onset of LH surge and is most active before ovulation; 3) the blood supply to the developing CL increases in parallel with CL volume and plasma progesterone concentrations; and 4) the local blood flow surrounding the mature CL acutely increases prior to the onset of luteolysis in response to uterine as well as exogenous $\mathrm{PGF}_{2 \alpha}$. It is now clear that color Doppler ultrasound is very useful for observing echogenicity with local blood flow thereby providing an easily obtained estimation of the physiological status of follicles, CLs and early conceptus. Widespread commercial application of color US will depend on further technological developments that reduce the cost and improve performance and ease-of-use. Overall, US is now a most effective non-invasive tool for managing reproduction, at the level of both the individual animal and the herd system. In particular, US can help us to clarify potential problems in high-producing dairy cattle during the postpartum period.
\end{abstract}

Key words: Color Doppler ultrasound, Blood flow, Ovary, Reproduction, Cow

(J. Reprod. Dev. 52: 153-160, 2006)

$\mathbf{U}$ ltrasonography (US) was first applied to clinical medicine mainly in ophthalmology in the beginning of 1960s [1, 2], and was rapidly adopted

in other areas of medicine including gynecology.

Correspondence: A. Miyamoto (e-mail: akiomiya@obihiro.ac.jp) 
Early gynecological usage focused on detection of the fetus in early pregnancy [3,4], and in 1970s detailed observations of the ovary with US began in conjunction with determination of plasma progesterone and estradiol concentrations by radioimmunoassay (RIA) which were becoming generally available [5-7]. In the late 1980s, US was applied to the ovary and uterus of domestic animals [8-12], and it was established in the 1990s as a practical tool for animal production. It was very clear that US was non-invasive and occurred in real-time. As the cow is a large animal, it was easy to use US for observation of the ovarian follicles and the corpus luteum (CL) repeatedly via transrectal scanning. This made it possible to observe the real-time dynamics of follicular development and enabled the discovery of follicular waves [10, 13, 14] which was not feasible in humans. This has greatly contributed to our understanding of ovarian physiology and aided development of several "pin-point" protocols for synchronization of estrus and ovulation. It is now well recognized that US is an essential tool to accurately detect early pregnancy as well as follicular waves, ovulation and CL formation which are important data used to achieve successful reproduction and dairy production. Moreover, we have used color Doppler US to observe local blood flow in individual follicles and the CL cows in both spontaneous and hormonally controlled estrus cycles, and found several essential physiological phenomena that were not detectable with imaging in black and white. This review will briefly describe the impact of US in reproductive physiology and in development of protocols for reproductive management that are non-invasive ("ethical") and non-hormonal ("clean"), and finally introduce our recent findings with color US to discuss its potential use for reproductive management of dairy cattle.

\section{Application of US for Examining Reproductive Physiology of the Cow}

After commencement of intensive research of the cow ovary in the late of 1980s, it became rapidly evident that cows have two or three follicular waves during the estrous cycle $[10,13,14]$. This discovery enabled better understanding of ovarian physiology in terms of the fine control of the endocrinology and dynamics of development and atresia of follicles. The direct relationship between the plasma profiles of FSH, estradiol and inhibin and each follicular wave [15-17], and the longer luteal phase of cows with three follicular waves followed by more rapid CL regression [14] were clearly demonstrated. Further detailed observations using US in conjunction with endocrinology showed that in dairy cows follicular dominance occurs when the largest follicle reaches a diameter of $8.5 \mathrm{~mm}[18,19]$. This observation accelerated the study of the microenvironment of dominant and atretic follicles, which lead to the concept that the rapid emergence of LH-receptor (LH-R) in granulosa cells in dominant follicles is a very sensitive and crucial autonomous system that determines the fate of follicles in the final stages of maturation $[18,19]$.

Ultrasonography of the ovary during the postpartum period demonstrated that the first follicular wave begins several days after parturition in most cows, and that those cows that ovulated the first or second follicular wave after parturition often had early resumption of ovarian activity and estrous cycles [20,21]. Ultrasonography also aided in defining the processes associated with formation of follicular cysts $[22,23]$ and demonstrated that cystic follicles commonly occurred repeatedly in the same cow. It is now generally accepted that negative energy balance during the postpartum period affects the concentrations of growth hormone, insulin, IGF-1 and leptin, and that these hormones may directly and indirectly regulate the hypothalamus-pituitary-ovarian axis [21, 24].

\section{Development of "Pin-point" Synchronization of Estrus and Ovulation Based on US}

The improved understanding of follicular waves described above, led to improved protocols using $\mathrm{PGF}_{2 \alpha}$ and /or GnRH for control of ovarian activity. The new protocols aimed to ensure that estrus and ovulation occurred at the optimal stage of follicle development and maturation. These new protocols aimed to induce ovulation and emergence of a new follicle wave, thus enabling optimal timing for GnRH-induced estrus and ovulation. Such programs have been widely and successfully applied commercially [25, 26]. However, this hormone-based approach does not appear to fit the 
concept of "clean, green and ethical". Theoretically, small to mid size dairy farms (up to 50-60 cows) do not necessarily need intensive hormonal treatment at all if the herds are relatively healthy and the farmers undertake efficient estrus detection. Unfortunately, this is not the usual situation, at least in Japan, and hence some, but not excessive usage of hormonal treatments is likely to be remain cost-effective for many farmers. Hormonal treatments, such as Ovsynch and Heatsynch, are undoubtedly needed to manage reproduction in large herds $[25,26]$. It is clear that the concept of "clean, green and ethical" is not "all or nothing", but rather that we should consider the balance of biological, environmental, welfare, and economic cost benefit of using such technology. The review papers of Dr. Martin and Dr. McDougall in this issue will provide good examples and describe the complexity of trying to achieve this balance [27, 28], and Dr. Kadokawa and Dr. Nakada will discuss in more detail the situation and application of the concept in Japan $[29,30]$.

\section{New Observations Using Color Doppler US that were not Possible with Imaging only in Black and White}

As described above, the black and white US has been helping us to understand a reproductive physiology and hence development of reproduction management system in the cow. To gain more precise information on the physiological status of the ovaries, we have begun to observe in detail the local blood flow in individual ovarian follicles and CLs using color Doppler US in the cow over the last few years. From this series of observations, we have found several fundamental phenomena that were not possible with imaging in black and white.

\section{1) Local blood supply to an individual follicle}

Using a sensitive high resolution Doppler US (SSD-1700 and SSD-5500, Aloka Co., Tokyo, Japan) equipped with a 7.5-MHz convex transducer (UST995-7.5, Aloka Co., Tokyo, Japan), we detected local blood flow in the theca externa of follicles. In the first follicular wave of cows, a trial was carried out to assess the presence or absence of blood flow for each follicle $>2.5 \mathrm{~mm}$ in diameter. Measurement of blood velocities in individual small follicles was not undertaken due to technical limitations [31]. Before follicle selection, there was no difference in the percentage of follicles with detectable blood flow in those follicles subsequently defined as the largest and in those follicles subsequently defined as the second largest follicles. Following follicle selection, blood flow was less likely to be detected in the second largest follicle compared to the largest follicle (Fig. 1). In addition, small follicles with detectable blood flow

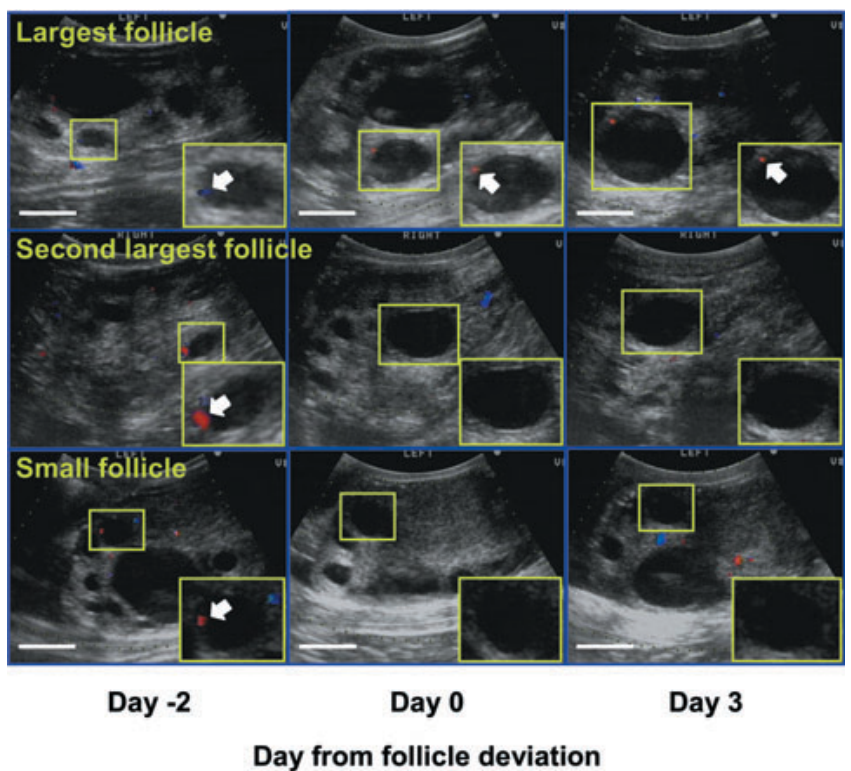

Fig. 1. Representative color Doppler images of the ovary around the day of follicle deviation [31]. Highlighted images show the largest (upper panel), second largest (middle panel) and a small follicle (lower panel) at Day -2, 0 and 3 from follicle deviation. Enlarged follicle images of the highlighted area show typical changes in detectable blood flow $(>2$ $\mathrm{mm} / \mathrm{sec}$ ). The arrow indicates areas with detectable blood flow within the follicle wall. After the follicle selection (Day 0), blood flow disappeared in the second largest and small follicles. Scale bar represents $1 \mathrm{~cm}$. 
one day before the occurrence of follicle selection, subsequently developed larger diameters than those without detectable blood flow at this time. It is likely that the maintenance of follicle vasculature and appropriate blood supply is essential for acquiring and maintaining follicular dominance. Consequently, the data strongly suggest that the change of the blood supply to an individual follicle closely relates to the dynamics of follicular growth and selection in the first follicular wave in the cow [31].

We also characterized the real-time changes in the blood flow in the theca externa of mature follicles associated with the LH surge and ovulation [32]. Cows with both spontaneous, and GnRHinduced, ovulation had a clear LH surge followed by ovulation $26-34 \mathrm{~h}$ later. Blood flow before the LH surge was only detectable in a small area in the base of the follicle (Fig. 2) [32]. An acute increase in the blood flow area and velocity was detected at 0 $6 \mathrm{~h}$ after the onset of the endogenous LH surge, or at $0.5 \mathrm{~h}$ after the $\mathrm{GnRH}$ injection, synchronous with the initiation of the LH surge (Fig. 2). The data confirm the concept that the complex structural and functional changes induced by the LH surge in a mature follicle are closely associated with a local increase in the blood flow within the preovulatory follicle wall.

Color images of an anovulatory follicle and a preovulatory follicle are shown in Fig. 3 [32]. The atretic follicle was characterized by a lack of detectable blood flow and a progressive decrease in

a) Spontaneous ovulation ( $\mathrm{h}=$ onset of LH surge)

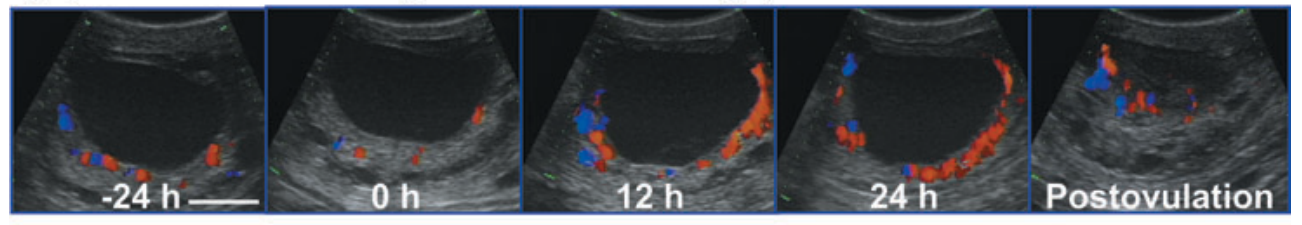

b) GnRH-induced ovulation ( $\mathrm{h}=\mathrm{GnRH}$ administration)

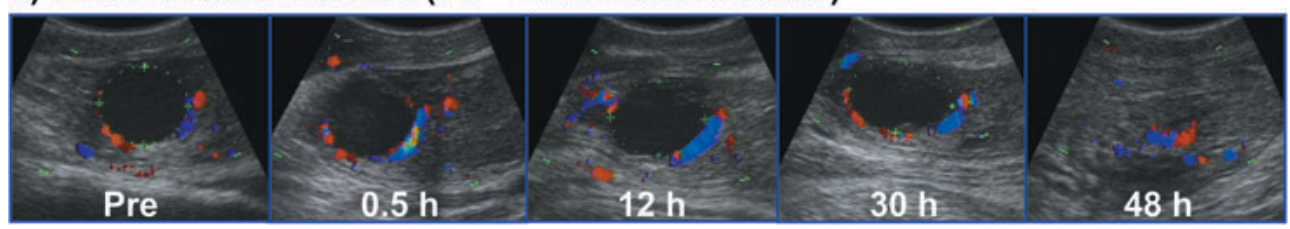

Fig. 2. (a) Images of the time-related changes in preovulatory follicle with spontaneous ovulation showing a gradual increase in the blood flow area as ovulation approaches [32; reproduced by permission]. (b) Images of preovulatory follicle following GnRH-induced ovulation show acute increases in the blood flow area and the intensity of color (velocity) after the injection of a GnRH analogue [32]. The color gain of the flow mode was set to detect movement of at least $2 \mathrm{~cm} / \mathrm{sec}$. Scale bar represents $1 \mathrm{~cm}$.

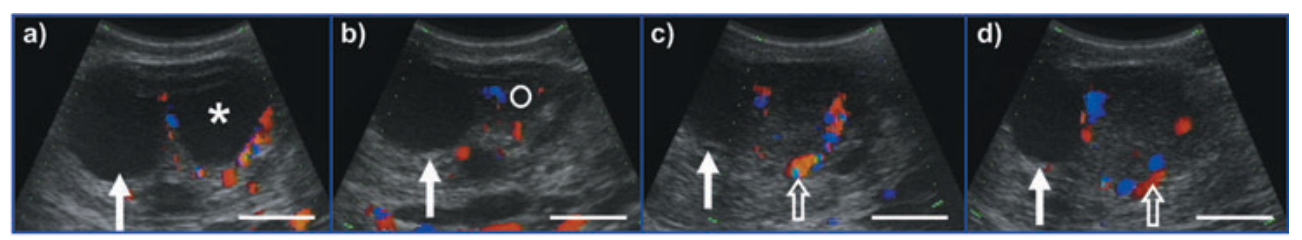

Fig. 3. Images of a preovulatory follicle $\left(^{*}\right)$ and an atretic follicle (closed arrow) of similar size showing clear differences in the vascularization and blood flow area in the follicular wall [32; reproduced by permission] (a) $24 \mathrm{~h}$ after a $\mathrm{GnRH}$ analogue injection, (b) just after ovulation (open circle), and (c,d) during early corpus luteum development (open arrows). The atretic follicle was still visible on Day 4 of the next cycle, but the antrum was not detected on Day 8. The color gain was set to detect movement of at least $2 \mathrm{~cm} / \mathrm{s}$. Scale bars represent $1 \mathrm{~cm}$. 
diameter. The preovulatory follicle was well vascularized with a detectable blood flow surrounding the antrum in the base of the follicle. The well-vascularized follicle ovulated (Fig. 3b) and a CL developed (Figs. 3c, d).

Ovarian cysts arise as a result of failure of ovulation of a preovulatory follicle. Some cysts are purely follicular (follicular cysts) with thin walls, whilst others (luteal cysts) have thicker luteinized walls. Persistent follicles maintain a detectable blood flow (Fig. 4a), and do not regress and become atretic and hence are defined as follicular cysts.

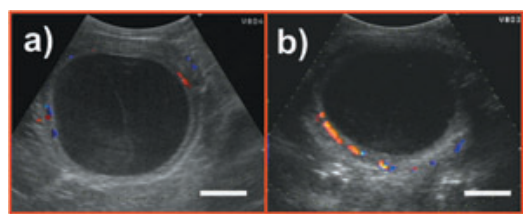

Fig. 4. Color Doppler images of a) follicular cyst and b) luteal cyst. Note the wall of luteal cyst between cystic cavity; a detectable blood flow ( $>2 \mathrm{~mm} / \mathrm{sec})$ is thick and surrounded with an active blood flow compared with follicular cyst. Scale bar represents $1 \mathrm{~cm}$.
Confirmation of the structure as a luteal or luteinized cyst can be made using color image which will show a thick wall $(>>4 \mathrm{~mm}$ ) of luteal tissue surrounded by an active blood flow (Fig. $4 \mathrm{~b}$ ).

\section{2) Local blood flow to the corpus luteum}

In the early CL, the blood flow (area and velocity) gradually increased in parallel with the increase in CL volume and plasma progesterone concentration from day 2 to day 5, indicating active angiogenesis and normal luteal development [32].

In the mature $\mathrm{CL}$, we investigated in detail the real-time changes in local blood flow within the CL around time of luteolysis. With spontaneous luteolysis, the blood flow surrounding the CL increased on days 17-18 in all cows examined $(n=$ 8 ), followed by a decrease in plasma progesterone concentration one day later (Fig. 5a) [33, 34]. Coincidentally, plasma PGFM concentrations drastically increased as luteal blood flow increased on days 17-18, strongly suggesting that pulsatile release of $\mathrm{PGF}_{2 \alpha}$ from the uterus stimulates the increase in luteal blood flow $[33,34]$. These results represent the first direct evidence in any

\section{a) Spontaneous luteolysis}

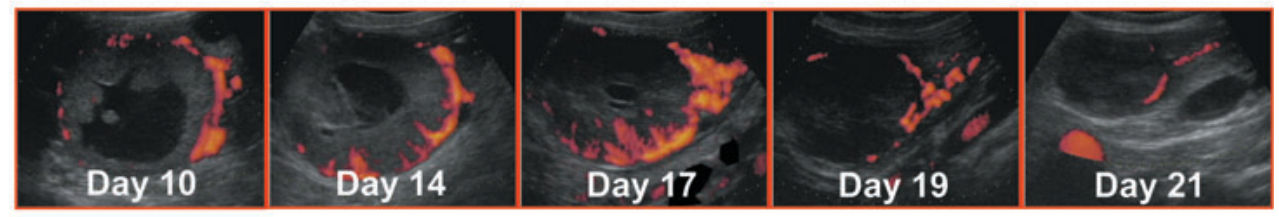

b) PGF $_{2 \alpha}$-induced luteolysis

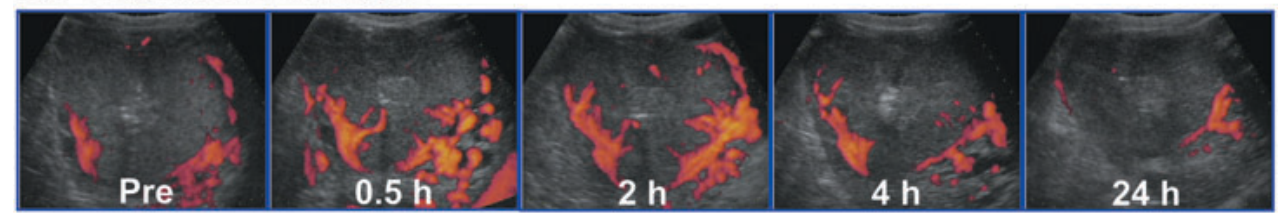

\section{c) PGF $_{2 \alpha}$-refractory developing $\mathrm{CL}$}

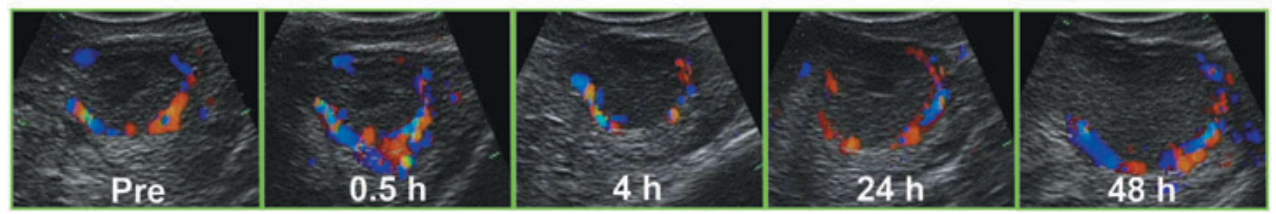

Fig. 5. These images show real-time changes of luteal blood flow area surrounding the corpus luteum in the cow [33-35; reproduced by permission]. a) luteal blood flow during spontaneous luteolysis from Day 10 to Day 21 of the estrous cycle, b) luteal blood flow during PGF $_{2 \alpha}$-induced luteolysis on Day 10 of the estrous cycle and c) luteal blood flow after a luteolytic dose of $\mathrm{PGF}_{2 \alpha}$ on Day 4 of the estrous cycle. Note that luteal blood flow does not change in spite of $\mathrm{PGF}_{2 \alpha}$ administration, and the CL continues to grow. 


\section{a) Anovulatory}

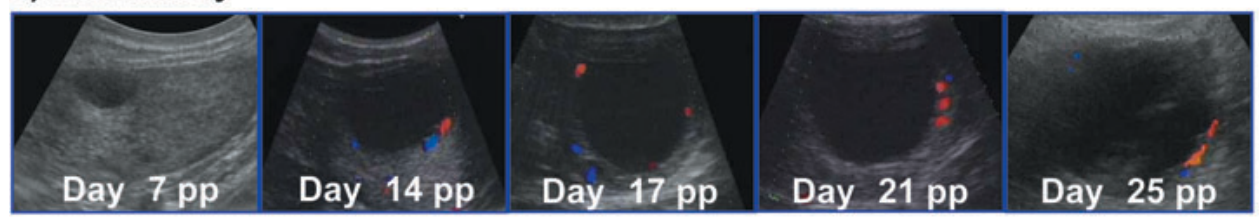

\section{b) Ovulatory}

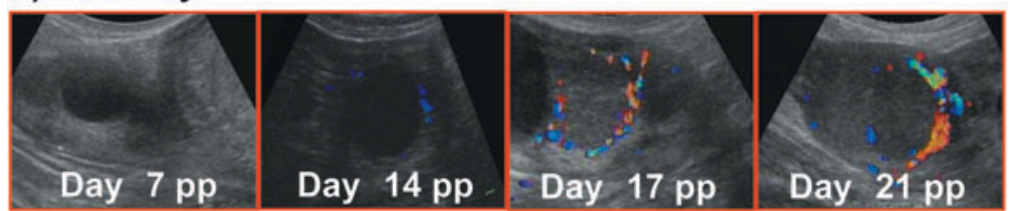

Fig. 6. Images of developing follicles during the postpartum period. a) Anovulatory follicles grow to larger than ovulatory size but are associated with low estradiol production. b) Ovulatory follicle with active estradiol production on day 14 postpartum, and the new CL started to develop on day 17 postpartum.

mammalian species that the luteal blood flow acutely increases before plasma progesterone concentration declines.

The blood flow response to $\mathrm{PGF}_{2 \alpha}$ injection was examined in both developing ( $\mathrm{PGF}_{2 \alpha}$-refractory) and mature $\left(\mathrm{PGF}_{2 \alpha}\right.$-sensitive) $\mathrm{CL}$. In the midcycle (mature) $\mathrm{CL}$, a luteolytic dose of $\mathrm{PGF}_{2 \alpha}$ analogue induced a very clear and acute increase in blood flow surrounding the CL (Fig. 5b) [35]. This acute increase was detected within $30 \mathrm{~min}$ and remained elevated up to $2 \mathrm{~h}$ after $\mathrm{PGF}_{2 \alpha}$ injection, followed by a gradual decrease (Fig. 5b). In contrast, these changes in blood flow were not observed in the developing CL (day 4), and the plasma progesterone and $\mathrm{CL}$ volume continued to increase (Fig. 5c) [35]. The fact that blood flow in the developing CL remains unchanged after $\mathrm{PGF}_{2 \alpha}$ injection, and that the CL does not regress, further supports the hypothesis that a direct relationship between an acute increase in luteal blood flow and luteolysis.

\section{3) Blood supply to the first ovulatory follicle during} the postpartum period and the early conceptus

We have also tried to investigate the local blood flow to the dominant follicle during the postpartum period. Interestingly, the first dominant follicle which appeared 1-2 weeks after parturition always had a detectable blood flow, irrespective of whether the follicle ovulated or became atretic. In the ovulatory cows, plasma estradiol was higher than those in anovulatory cows, indicating that the

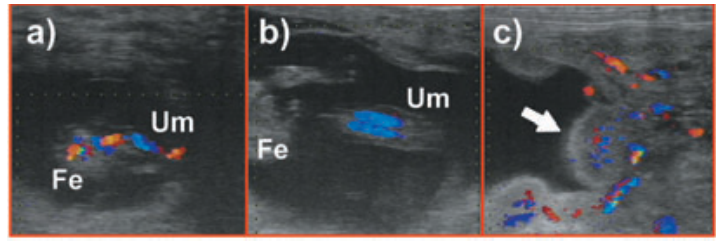

Fig. 7. Representative color Doppler images of the early conceptus. a) Blood flow was detected in fetus (Fe) and umbilical cord (Um) at Day 39 of pregnancy. b) Blood flow of Um (Day 60) increased in size with gestation period. c) Caruncles/cotyledons (arrow, Day 60) contained active blood flow.

anovulatory follicle was growing to the ovulatory size but was producing only small amounts of estradiol (Fig. 6). Further investigations of follicles as well as the CL are necessary to understand ovarian physiology of postpartum cows.

The color US was also used to describe the local blood flow associated with the early conceptus. Active blood flow were detected in the fetus, umbilical cord and placenta (Figs. 7a-c). Almost all fetal losses are known to occur by day 60 of pregnancy as defined by milk progesterone profiles [36]. However, progesterone levels may not always be a reliable indicator of the time of loss, because in some cases they may remain high after a fetal death. Therefore, the color US may also allow a better understanding of the pathophysiology of fetal loss. 


\section{Conclusion}

Using the US technology that is now commercially available at a reasonable price, we are able to estimate the best timing for $\mathrm{AI}$ and this allows us to plan the use of precisely-timed nutritional supplements for fetal development or to determine whether PG or other treatment is appropriate for the immediate 2 nd AI service to achieve a better economic outcome. While US may not seem to fit preconceived ideas of a "green" technology, it does not contravene environmental priorities, and it is non-invasive ("ethical") and non-hormonal ("clean"). It is now clear that color Doppler ultrasound is very useful for observing echogenicity with local blood flow thereby providing an easily obtained estimation of the physiological status of follicles, CL's and the early conceptus. Widespread commercial uptake of color US awaits further development of the technology and demonstration of its performance, its ease-ofuse and its cost-effectiveness. Overall, US is now a most effective non-invasive tool for managing reproduction, at the level of both the individual animal and at the herd level. In particular, US can help us to clarify potential problems in highproducing dairy cattle during the postpartum period.

\section{Acknowledgments}

This study was supported by the Grant-in-Aid for Scientific Research of the Japan Society for the Promotion of Science (JSPS), the 21st Century COE Program (A-1) of Ministry of Education, Culture, Sports, Science, and Technology, Japan. K.S. and K.G.H. are supported by JSPS Research Fellowships for Young Scientists.

\section{References}

1. Baum G, Greenwood I. Ultrasonography-an aid in orbital tumor diagnosis. Arch Ophthalmol 1960; 64: 180-194.

2. Oksala A. The clinical value of time-amplitude ultrasonography. Am J Ophthalmol 1964; 57: 453-460.

3. Andrew DS. Ultrasonography in pregnancy-an enquiry into its safety. Br J Radiol 1964; 37: 185-186.

4. Durkan JP, Russo GL. Ultrasonic fetal cephalometry: accuracy, limitations, and applications. Obstet Gynecol 1966; 27: 399-403.

5. Piiroinen O, Kaihola HL, Kivikoski A, Rauramo L. Bleeding in early pregnancy investigated by ultrasound, plasma progesterone and oestradiol. Ann Chir Gynaecol Fenn 1974; 63: 451-456.

6. Hackeloer BJ, Robinson HP. Ultrasonic demonstration of follicle and corpus luteum development in normal menstrual cycle and its relation to hormone profiles. Arch Gynecol 1979; 228: 556-558.

7. Robertson RD, Picker RH, Wilson PC, Saunders DM. Assessment of ovulation by ultrasound and plasma estradiol determinations. Obstet Gynecol 1979; 54: 686-691.

8. Quirk SM, Hickey GJ, Fortune JE. Growth and regression of ovarian follicles during the follicular phase of the oestrous cycle in heifers undergoing spontaneous and $\mathrm{PGF}_{2 \alpha}$-induced luteolysis. J Reprod Fertil 1986; 77: 211-219.

9. Kahn W. Occurrence and growth dynamics of the cystic corpora lutea in the estrus cycle of cattle and their hormone profile. Dtsch Tierarztl Wochenschr 1986; 93: 475-480.

10. Savio JD, Keenan L, Boland MP, Roche JF. Pattern of growth of dominant follicles during the oestrous cycle of heifers. J Reprod Fertil 1988; 83: 663-671.

11. Ginther OJ, Knopf L, Kastelic JP. Ovarian follicular dynamics in heifers during early pregnancy. Biol Reprod 1989; 41: 247-254.

12. Lucy MC, Staples CR, Michel FM, Thatcher WW. Energy balance and size and number of ovarian follicles detected by ultrasonography in early postpartum dairy cows. J Dairy Sci 1991; 74: 473-482.

13. Sirois J, Fortune JE. Ovarian follicular dynamics during the estrous cycle in heifers monitored by real-time ultrasonography. Biol Reprod 1988; 39: 308317.

14. Ginther OJ, Knopf L, Kastelic JP. Temporal associations among ovarian events in cattle during oestrous cycles with two and three follicular waves. J Reprod Fertil 1989; 87: 223-230.

15. Ginther OJ, Bergfelt DR, Kulick LJ, Kot K. Selection of the dominant follicle in cattle: Role of two-way functional coupling between folliclestimulating hormone and the follicles. Biol Reprod 2000; 62: 920-927.

16. Ginther OJ, Beg MA, Bergfelt DR, Donadeu FX, Kot K. Follicle selection in monovular species. Biol Reprod 2001; 65: 638-647.

17. Mihm M, Crowe MA, Knight PG, Austin EJ. Follicle wave growth in cattle. Reprod Domest Anim 
2002; 37: 191-200.

18. Ginther OJ, Wiltbank MC, Fricke PM, Gibbons JR, Kot K. Selection of the dominant follicle in cattle. Biol Reprod 1996; 55: 1187-1194.

19. Beg MA, Bergfelt DR, Kot K, Wiltbank MC, Ginther OJ. Follicular-fluid factors and granulosacell gene expression associated with follicle deviation in cattle. Biol Reprod 2001; 64: 432-441.

20. Savio JD, Boland MP, Roche JF. Development of dominant follicles and length of ovarian cycles in post-partum dairy cows. J Reprod Fertil 1990; 88: 581-591.

21. Beam SW, Butler WR. Effects of energy balance on follicular development and first ovulation in postpartum dairy cows. J Reprod Fertil 1999; 54 (Suppl) : 411-424.

22. Cook DL, Smith CA, Parfet JR, Youngquist RS, Brown EM, Garverick HA. Fate and turnover rate of ovarian follicular cysts in dairy cattle. J Reprod Fertil 1990; 90: 37-46.

23. Hamilton SA, Garverick HA, Keisler DH, Xu ZZ, Loos K, Youngquist RS, Salfen BE. Characterization of ovarian follicular cysts and associated endocrine profiles in dairy cows. Biol Reprod 1995; 53: 890-898.

24. Armstrong DG, Gong JG, Webb R. Interactions between nutrition and ovarian activity in cattle: physiological, cellular and molecular mechanisms. Reproduction 2003; 61 (Suppl) : 403-414.

25. Gumen A, Guenther JN, Wiltbank MC. Follicular size and response to Ovsynch versus detection of estrus in anovular and ovular lactating dairy cows. $J$ Dairy Sci 2003; 86: 3184-3194.

26. Kasimanickam R, Cornwell JM, Nebel RL. Fertility following fixed-time AI or insemination at observed estrus in Ovsynch and Heatsynch programs in lactating dairy cows. Theriogenology 2005; 63: 2550 2559.

27. Martin GB, Kadokawa H. "Clean, green and ethical" animal production. case study: Reproductive efficiency in small ruminants. J Reprod
Dev 2006; 52: 145-152.

28. McDougall S. Reproduction performance and management of dairy cattle. J Reprod Dev 2006; 52: 185-194.

29. Kadokawa $\mathbf{H}$. A new perspective on management of reproduction in dairy cows: the need for detailed metabolic information, an improved selection index and extended lactation. J Reprod Dev 2006; 52; 161168.

30. Nakada K. How to improve reproductive efficacy from now in Japan? Find out the factors of late lactation to predict postpartum reproductive diseases. J Reprod Dev 2006; 52: 177-183.

31. Acosta TJ, Hayashi KG, Matsui M, Miyamoto A. Changes in follicular vascularity during the first follicular wave in lactating cows. J Reprod Dev 2005; 51: 273-280.

32. Acosta TJ, Hayashi KG, Ohtani M, Miyamoto A. Local changes in blood flow within the preovulatory follicle wall and early corpus luteum in cows. Reproduction 2003; 125: 759-767.

33. Shirasuna K, Wijayagunawardane MP, Watanabe S, Yamamoto D, Matsui M, Ohtani M, Miyamoto A. A blood flow in the corpus luteum acutely increases together with endothelin-1 mRNA expression at early stage of regression during spontaneous luteolysis in the cow. Biol Reprod 2004; 71: 137 (Abstract 194).

34. Miyamoto A, Shirasuna K, Wijayagunawardane MP, Watanabe S, Hayashi M, Yamamoto D, Matsui M, Acosta TJ. Blood flow: A key regulatory component of corpus luteum function in the cow. Domest Anim Endocrinol 2005; 29: 329-339.

35. Acosta TJ, Yoshizawa N, Ohtani M, Miyamoto A. Local changes in blood flow within the early and midcycle corpus luteum after prostaglandin $F_{2 \alpha}$ injection in the cow. Biol Reprod 2002; 66: 651-658.

36. Ball PHJ, Peters AR. Reproductive problem. In: Reproduction in Cattle. Oxford: Blackwell publishing; 2004: 154-190. 